DOI: 10.36910/6775-2524-0560-2019-36-16

УДК 616.5-006.81

Акимов В. С.

Національний технічний університет України «Київський політехнічний інститут імені Ігоря Сікорського»

\title{
АЛГОРИТМИ БАГАТОРІВНЕВОГО НАВЧАННЯ ДЛЯ ВИРІШЕННЯ ЗАДАЧІ КЛАСИФІКАЦІї ЗАХВОРЮВАНЬ ШКІРИ
}

\begin{abstract}
Акимов В. С. Алгоритми багаторівневого навчання для вирішення задачі класифікації захворювань шкіри. Захворювання шкіри сьогодні належать до розповсюджених медичних проблем. Кількість таких захворювань постійно зростає, незважаючи на розвиток медичної галузі. Рак шкіри є поширеним злоякісним новоутворенням і займає друге рангове місце у структурі онкологічної захворюваності населення України. Первинна діагностика таких хвороб здійснюється візуально, починаючи 3 клінічних обстежень, що можуть супроводжуватись дерматоскопічним аналізом, біопсією та гістопатологічною експертизою. У роботі виконано аналіз існуючих наукових публікацій щодо класифікації захворювань шкіри при використанні згорткових нейронних мереж, який показав, що на сьогодні існує незначна кількість публікацій з використанням глибокого навчання. Результати існуючих досліджень не містять достатнього рівня точності і результативності щодо класифікації захворювань шкіри, що підтверджує необхідність розробки нових згорткових нейронних мереж і їх подальших досліджень. Тому у роботі запропоновано технічне рішення щодо побудови згорткової нейронної мережі для класифікації захворювань шкіри.

Ключові слова: класифікація захворювань шкіри, дерматоскопічні зображення, згорткові нейронні мережі, глибоке навчання.

Акимов В. С. Алгоритмы многоуровневого обучения для решения задачи классификации заболеваний кожи. Заболевания кожи сегодня относятся к распространенным медицинским проблемам. Количество таких заболеваний постоянно растет, несмотря на развитие медицины. Рак кожи является распространенным злокачественным новообразованием и занимает второе ранговое место в структуре онкологической заболеваемости населения Украины. Первичная диагностика таких болезней осуществляется визуально, начиная с клинических обследований, которые могут сопровождаться дермоскопическим анализом, биопсией и гистопатологичной экспертизой. В работе выполнен анализ существующих научных публикаций по классификации заболеваний кожи при использовании сверточных нейронных сетей, который показал, что на сегодняшний день существует незначительное количество публикаций, где используется глубокое обучение. Результаты существующих исследований не обладают достаточным уровнем точности и результативности по классификации заболеваний кожи, что подтверждает необходимость разработки новых сверточных нейронных сетей и их дальнейшем исследовании. Поэтому в работе предложено техническое решение по построению сверточной нейронной сети для классификации заболеваний кожи.
\end{abstract}

Ключевые слова: классификация заболеваний кожи, дермоскопические изображения, сверточные нейронные сети, глубокое обучение.

Akymov V. S. Algorithms for multi-level learning to solve the problem of classifying skin diseases. Skin diseases today are common medical problems. The number of such diseases is constantly growing, despite the development of medicine. Skin cancer is a common malignant neoplasm and takes the second ranking place in the structure of cancer incidence in Ukraine. Primary diagnosis of such diseases is carried out visually, starting with clinical examinations, which may be accompanied by dermoscopy analysis, biopsy and histopathological examination. The paper analyzes the existing scientific publications on the classification of skin diseases using convolutional neural networks, which showed that today there are a small number of publications that use deep learning. The results of existing studies do not have a sufficient level of accuracy and effectiveness in the classification of skin diseases, which confirms the need to develop new convolutional neural networks and their further study. Therefore, the paper proposed a technical solution for constructing a convolutional neural network for the classification of skin diseases.

Key words: skin diseases classification, dermatoscopy images, convolutional neural networks, deep learning.

Постановка наукової проблеми. Захворювання шкіри сьогодні належать до розповсюджених медичних проблем. Кількість таких захворювань постійно зростає, незважаючи на розвиток медичної галузі. Рак шкіри $€$ поширеним злоякісним новоутворенням з середньорічним темпом приросту до 5\% і може вважатися одним з найвищих серед усіх злоякісних пухлин, крім раку легені [1]. Первинна діагностика таких хвороб здійснюється візуально, починаючи з клінічних обстежень, що можуть супроводжуватись дерматоскопічним аналізом, біопсією та гістопатологічною експертизою [1].

Автоматизована класифікація уражень шкіри 3 використанням зображень $\epsilon$ складним завданням через дрібнозернисту мінливість появи уражень шкіри. Глибокі згорткові нейронні (ЗНМ) (англ. convolutional neural network, CNN, ConvNet) показують потенціал для загальних i спеціалізованих завдань за багатьма дрібнодисперсними категоріями об’єктів.

Відомо, що зміни в структурі шкіри являють собою індикатор різних захворювань, включаючи рак шкіри, який є однією з основних проблем зі здоров'ям у всьому світі [1]. Існує кілька типів уражень шкіри, в тому числі меланома, базальноклітинний рак, меланоцитарний невус, берматофіброма, доброякісний кератоз, актинічний кератоз і судинне ураження. Раннє виявлення, 
ідентифікація і класифікація типу ураження займають важливу роль в діагностиці та стратегії лікування. Лікарі покладаються на свій візуальний досвід, щоб оцінити індивідуальність пацієнтів на основі місцевих патернів ураження в порівнянні зі шкірою інших ділянок тіла [2]. Проте, автоматичний аналіз і класифікація дерматоскопічних зображень забезпечують точну і своєчасну оцінку типу ураження шкіри відповідно до структури уражених ділянок тіла [3]. У попереднє десятиріччя [4-10], була виконана класифікація дерматоскопічних зображень шкірних утворень, в якій застосовані: штучна нейронна мережа (ШНM) [4], метод опорних векторів (MOB, англ. SVM) [5, 6], модель мішків з особливостями [7], дерево рішень [8], ансамблева класифікація [9] і класифікатори на основі нечіткої логіки [10]. У порівнянні зі статистичними методами [11], ЗНМ забезпечує меншу частоту помилок, при цьому відбувається зіставлення набору ознак або симптомів 3 ймовірними діагностичними класами. Але набір даних не може бути отриманий $з$ нейронної мережі (HМ), оскільки її параметри виводяться безпосередньо. Крім того, процес класифікації зображень для дерматоскопії ускладнюється наявністю артефактів, шумів, складності та мінливості структур ураження шкіри, зміни освітленості в процесі захвату зображення, густих волосків, бульбашок повітря і низького контрасту між зображеннями здорової шкіри і уражених ділянок.

За допомогою глибокого навчання (ГН) застосовується кілька варіантів класифікації [1]. Алгоритми ГН пропонують архітектуру систем машинного навчання, яка заснована на здатності обробляти великі набори даних за допомогою техніки розпаралелювання складних обчислень. Для класифікації медичних зображень ЗНМ вважаються найбільш поширеною архітектурою для деяких додатків $[1,3]$. ЗНМ має значну концептуальну основу, що включає поділ ваг, локальне сприйняття області і тимчасову область або простір понижувальної дискретизації, які гарантують відносні незмінні характеристики зміщення, спотворення і масштабування. Для класифікації уражень шкіри існує незначна кількість досліджень щодо застосування ЗНМ для розпізнавання, але, слід зазначити про проекти ЗНM, такі як Inception (GoogleNet), AlexNet, QuocNet, BNInception-V2 i Inception-V3 [2, $4,5,10,12-23]$. Поряд 3 тим, необхідно виконати аналіз існуючих досліджень 3 розглядаємої проблеми класифікації уражень шкіри.

Аналіз досліджень. Серед праць, присвячених багаторівневому навчанню для вирішення задачі класифікації захворювань шкіри, слід відмітити [12-23], які стосуються мети наукової праці, іiі завдань, предмета та об'єкта. Перш за все, це роботи, в яких розглядаються задачі класифікації захворювань шкіри на основі ЗНМ з використанням ГН. До авторів, доробок яких привертає увагу 3 цих позицій, можна віднести, таких як: Haenssle H.A., Fink C., Schneiderbauer R., Toberer F., Buhl T., Blum A., Kalloo A.A., Hassen A. B. H., Thomas L., Enk A., UhlmaHM L., Наo Chang, Гаврилов Д.А. і ін.

Виділення невирішених раніше частин загальної проблеми. В умовах України не існує систем класифікації або ЗНМ, призначених для вирішення задачі класифікації захворювань шкіри, а також застосування ГН при цьому. Тому актуальним $є$ проведення аналізу існуючих наукових публікацій щодо класифікації захворювань шкіри при використанні ЗНМ, а на основі аналізу розробити технічне рішення щодо побудови ЗНМ з ГН для класифікації захворювань шкіри.

Метою роботи $є$ аналіз існуючих наукових публікацій щодо класифікації захворювань шкіри при використанні ЗНМ та розробка технічного рішення щодо побудови ЗНМ з ГН для класифікації захворювань шкіри.

Виклад основного матеріалу й обгрунтування отриманих результатів дослідження.

Для розробки технічного рішення щодо побудови ЗНМ з ГН для класифікації захворювань шкіри виконаємо повний аналіз наукових праць [12-23]. Так, у роботі [12] наведено порівняльні результати діагностичних показників ЗНМ і міжнародної групи з 58 дерматологів, включаючи 30 експертів при виявленні меланоми. Архітектура Google Inception v4 3НM була навчена і перевірена 3 використанням дерматоскопічних зображень і відповідних діагнозів. У порівняльному дослідженні 3 використанням рідера використовувався тестовий набір із 100 зображень (рівень I - тільки дерматоскопія; рівень II - дерматоскопія плюс клінічна інформація і зображення). Основними критеріями оцінки були чутливість, специфічність і площа під кривою (AUC) робочих характеристик приймача (ROC) для діагностичної класифікації (дихотомічних) уражень шкіри ЗНМ у порівнянні 3 міжнародною групою дерматологів. На I рівні дерматологи досягли середньої чутливості і точності класифікації захворювань шкіри 86,6\% і 71,3\% відповідно. Більше клінічної інформації (рівень II) поліпшило чутливість до $88,9 \%$ і точність до 75,7\%. Крива ROC 3НM показала більш високу точність $82,5 \%$ в порівнянні 3 дерматологами на рівні I $(71,3 \%, \mathrm{P}<0,01)$ і рівні II $(75,7 \%, \mathrm{P}<0,01)$ при їх чутливості 86, 6\% і 88,9\% відповідно; AUC 3HM ROC була більше, ніж середня площа ROC дерматологів $(0,86$ проти $0,79, \mathrm{P}<0,01)$. У результаті, в роботі зроблено висновок про те, що більшість дерматологів перевершило ЗНМ. Однак кожному дерматологу може допомогти 
класифікація зображень ЗНМ. Відповідно, автори роблять висновок про необхідність подальших удосконалень класифікації зображень ЗНМ з наступними дослідженнями.

На думку автора, наведені результати досліджень підтверджують вірний напрям, в якому необхідно рухатись, щоб досягти найкращих результатів щодо класифікації уражень шкіри.

У [13] виконали подальші спроби, відштовхуючись від праці [13], де була зроблена спроба ототожнення роботи ЗНМ і дерматолога. Оскільки НМ є наближеннями до функції чорного ящика, а медичному експерту важко міркувати про їх результати, то він не довірятиме мережі в разі незгоди 3 iï висновками. У такому випадку пояснення того, чому ЗНМ приймає певне рішення, стає цінною інформацією. У роботі показано, що, в деякій мірі, ЗНМ базуються на функціях, аналогічних тим, які використовуються дерматологами для постановки діагнозу. Проте, необхідні додаткові дослідження для повного пояснення їх результатів. У роботі використовувалася ЗНМ 3 попередньо навченої великою базою даних зображень, таких як ImageNet, 3 точним налаштуванням цільового набору даних. Досліджувана ЗНМ представлена 4 згортковими блоками, кожен 3 яких утворений 2 згортковими шарами, за якими слідує операція максимального об'єднання. Згорткові шари в кожному блоці мали розмір ядра $3 \times 3$ з 8, 16, 32 і 64 фільтрами. Далі слідували 3 повністю пов'язаних шари 3 2056, 1024 і 64 прихованими шарами. Усі шари мають випрямлені лінійні одиниці (ReLU) у вигляді нелінійності. Ефективність, що отримана в результаті обробки ЗНМ, перевірялася на тестовому наборі, що складався з 600 зображень для дерматоскопії (483 доброякісних уражень, 117 злоякісних уражень), досягнула показника AUC 0,75. Встановлено, що згорткові шари високого рівня активуються за тими ж критеріями, які використовуються дерматологами, такими як межа ураження, більш темні області всередині ураження, навколишня шкіра тощо. Відзначається про результати, які дають певне уявлення про особливості вивчених ЗНМ, але, які не пояснюють причинно-наслідковий зв'язок між виявленими особливостями ЗНМ і їі вихідними даними. Автори вважають, що необхідні додаткові дослідження в області визначення окремих структур шкіри (глобули, точки, структури кровоносних судин тощо), які визначають дерматологи, з метою зробити ЗНМ кращим інструментом підтримки прийняття рішень для дерматологів.

Безперечно, людина-професіонал може краще виконати аналіз і зробити висновки, ніж застосовані ЗНМ. Але, якщо ЗНМ будуть навчати такі професіонали, то можна в майбутньому досягти ліпших результатів і різниці між висновками ЗНМ і лікарями не спостерігатиметься.

У роботі [14] запропоновано нову стратегію, що заснована на техніці глибокого навчання, 3 досягненням дуже високої сегментації ураження шкіри і точності діагностики меланоми. При цьому була побудована НM сегментації (skin_segHM), яка досягла дуже високої точності виявлення межі ураження, а також побудована глибока ЗНМ в Google Inception v3 (skin_re3HM) 3 добре навченими вагами, що дозволяє досягти високої точності прогнозування. Було досліджено 2000 дерматоскопічних зображень, що включають 374 зображення меланоми, 1372 зображення невуса i 254 зображення себорейного кератозу. У процесі навчання і тестування НМ не була використана інформація про пацієнтів, хоча і відомо, що меланома залежить від віку і статі. НМ сегментації ураження шкіри (skin_segHM) подібна архітектурі U-Net, імплементація якої може бути здійснена на базі таких інструментів як Tensorflow, Theano i Keras. Архітектура skin_segHМ включає в себе ряд згорткових і відокремлюючих шарів. НM розпізнавання меланоми (skin_re3HM) побудована на основі backbend мережі Google Inceptions V3. Вихідний шар Inceptions V3 замінений на повний рівень з'єднань (1024 вузла). В архітектурі є дві HM Inceptions V3, одна відповідає за повнорозмірні дерматоскопічні зображення, інша - за обрізання дерматоскопічного зображення 3 skin_segHM, яка підтримувала тільки велику ділянку ураження. Потім обидва (1024) вузла об'єднуються, і нижче зв'язується вихідний шар з 3 вузлами. Ці 3 вузли представляють 3 класи, включаючи меланому, невус i себорейний кератоз. Навчання мережі відбувається із заморожуванням всіх шарів Inception V3, a останні два блоки шарів $€$ шари навчання, 3 дуже низькою швидкістю оптимізації. У підсумку робиться висновок, що добре навчені дерматологи домінують в діагностичної точності. Тобто необхідні подальші розробки систем автоматичного аналізу зображень для підвищення їх точності.

Результати роботи підтверджують необхідність вдосконалення ЗНМ для досягнення найкращого результату з класифікації медичних зображень захворювання шкіри.

У роботах [15-17] запропоновано алгоритм для первинної діагностики меланоми шкіри на основі глибоких ЗНМ, які досягають точності визначення меланоми в $91 \%$ на дерматоскопічних зображеннях. Даний алгоритм реалізований i доступний в тестовій версії за адресою skincheckup.online. Архітектура НM заснована на Inception v.3 з пакетною нормалізацією Ваtсh normalization, шар якого міститься в кожному блоці з двох згорток, що дозволяє істотно прискорити процес навчання ЗНМ зі зниженням імовірності перенавчання. Для підвищення якості розпізнавання і класифікації, всього було навчено 5 НМ з однаковою архітектурою, але, які мають різні ваги і, що 
об'єднувалися в один ансамбль. Авторами відзначається отримання високих результатів використання даних ЗНM, які можуть бути використані для створення вбудованих систем, WEB i мобільних додатків, що вимагає подальших досліджень.

Приведені дані, є дещо сумнівними, оскільки, точність визначення сягає занадто високих значень з розпізнавання меланоми шкіри з використанням ЗНМ з ГН.

У [18] подано класифікацію уражень шкіри з використанням однієї ЗНМ, безпосередньо навченої наскрізними зображеннями, використовуючи тільки пікселі і мітки хвороб в якості вхідних даних. Навчання ЗНМ виконувалося з використанням набору даних з 129450 клінічних зображень. Досліджено використання бінарної класифікації: карциноми кератиноцитів в порівнянні 3 доброякісними себорейними кератозами і злоякісні меланоми в порівнянні 3 доброякісними невусами. Перший випадок являє ідентифікацію найбільш поширених видів раку, другий являє ідентифікацію смертельного раку шкіри. ЗНМ досягає продуктивності нарівні 3 усіма протестованими експертами в обох задачах, демонструючи штучний інтелект, що здатний класифікувати рак шкіри 3 рівнем компетентності, порівнянним 3 дерматологами. У роботі використана архітектура GoogleNet Inception v3 3НM, яка була попередньо навчена приблизно на 1,28 млн. зображень (1000 категорій об'єктів) і навчена за допомогою перенесення. Також ЗНМ навчена 3 використанням 757 класів хвороби, організованих у вигляді дерева таксономії 2032 хвороб, в яких окремі хвороби утворюють вузли. При цьому отримані результати досліджуваної ЗНМ досягають $72,1 \pm 0,9 \%$ загальної точності, а два дерматолога $-65,56 \%$ і $66,0 \%$ точності в підмножині набору перевірки. При поділі хвороб за дев'ятьма класами, ЗНМ досягає 55,4 $\pm 1,7 \%$ загальної точності, тоді як ті ж два дерматолога досягають 53,3\% і 55,0\% точності. Авторами наголошується, що мобільні пристрої, оснащені глибокими НМ, потенційно можуть розширити охоплення дерматологів за межами клініки, забезпечуючи недорогий універсальний доступ до життєво важливої діагностичної допомоги. Крім того, наголошується, що наведений метод в основному обмежений даними і може класифікувати багато візуальних умов, якщо існує достатня кількість навчальних прикладів.

Отримані дані можна ототожнювати з дійсними, оскільки в даній роботі враховані похибки і автори наводять дані з алгоритмів навчання ЗНМ і порівнюють їх з висновками двох дерматологів.

У роботі [19] запропоновано систему для обробки зображень, яка представляє собою ансамбль з десяти ЗНМ, що працюють паралельно, і однієї мережі, що використовує їх результати для вироблення остаточного рішення. Така структура системи дозволяє підвищити ефективність іï роботи на кілька процентних пунктів у порівнянні з однією НМ. Запропонована система навчена більш ніж на 5000 і згодом протестована на 200 родимках шкіри. При цьому була використана згорткова фільтрація, а також метод сегментації ураження шкіри. Результати виявилися дуже обнадійливими: система досягла високих результатів класифікації: 85\% AUC, 84\% точності, 91\% чутливості і $78 \%$ специфічності в середньому. Приблизно такі ж результати, отримані за допомогою методів глибокого навчання були досягнуті і в роботах [20-22]. Авторами відзначено, що розроблена система може бути використана в якості системи підтримки прийняття рішень для лікарів первинної медичної допомоги, як система, здатна до самоаналізу шкіри за допомогою дерматоскопії, а також як важливий інструмент для поліпшення процесу прийняття рішень 3 біопсії.

На думку автора, наведені результати досліджень становлять інтерес і підтверджують необхідність у розробці і нових дослідженнях ЗНМ з ГН для поліпшення результатів щодо класифікації уражень шкіри.

Робота [23] спрямована на поліпшення автоматичної класифікації уражень шкіри, а дослідження включали набір даних з 10015 дерматоскопічних тренувальних зображень 7 різних типів уражень шкіри для стимулювання розробки автоматичних 7-здатних методів класифікації, а саме: меланома (MEL), меланоцитарний невус (NV), базальноклітинний рак (BCC), актинічний кератоз (AKIEC), доброякісний кератоз (BKL), дермато-брому (DF) i судинні ураження (VASC). Використовувалася платформа DenseNets, в якій перша модель була призначена для класифікації між доброякісними ураженнями і іншими, а друга модель - виконує детальну класифікацію за іншими 6 класами. У цілому обидві моделі демонструють однакову продуктивність в перевірочному наборі даних. Автори відзначають про відсутність прогресу в навчанні для певних класів, таких як MEL або AKIEC, що пов'язано з відсутністю достатньої інформації для навчання класифікатора для даних класів. Тому необхідно продовжити дослідження.

Приведені дані підтверджують необхідність значної вибірки медичних зображень захворювань шкіри для навчання ЗНМ з отриманням більш значущих результатів.

Авторами роботи [24] досліджено припущення про те, що сегментація покращує класифікацію уражень шкіри з використанням ЗНМ. Перевірка класифікації з використанням різних ступенів сегментації зображень 3 архіву даних ISIC (1279 зображень уражень шкіри і відповідних 
бінарних масок 3 нанесеними мітками уражень) 3 архітектурою VGG-16 показала несподівані результати. Набір даних був попередньо розділений на 900 навчальних зображень і 379 тестових зображень. Замість того, щоб навчати модель ЗНМ з нуля з використанням невеликого набору даних, був реалізований підхід до навчання переносу, який витягує шари з НM, раніше навченої на іншому, більшому наборі даних [25]. На основі VGGNet, яка показала високі результати [26], побудована 3НM, що навчена на наборі даних ImageNet, який містить понад 14 мільйонів природних зображень [27]. Архітектура VGG-16 складається 3 п'яти згортальних блоків і модифікованого остаточного повністю підключеного блоку (256), з функцією активації ReLU i одного сигмоїдального вузла. Були заморожені перші чотири згортальних блоки, ініціалізували повністю зв'язані шари з рівномірним розподілом (процес, відомий як рівномірна ініціалізація), а потім виконали навчання ЗНМ за допомогою зображень. Перші результати показали, що найвища ефективність класифікації має місце, коли виконується сегментація 3 попередньою класифікацією і нетрадиційна подальша дилатація області сегментації. Точність і чутливість бінорного класифікатора ЗНМ, яка виявляє меланому на дерматоскопічних зображеннях, підвищується 3 використанням сегментованих зображень (зображень, які містять тільки ураження і виключають дані, що оточують ураження). При цьому точність, чутливість і AUC покращилися, коли до зображень з набору даних ISIC була застосована ідеальна сегментація. 3 трьох показників ефективності, чутливість була найбільш покращена, збільшившись з $24,0 \%$ до 45,3\%. Автори зазначають, що у майбутній роботі слід розробити ефективні методи сегментації і вивчити вплив включення даних, що оточують ураження, під час класифікації.

Приведена група робіт вказує на необхідність виконання сегментації для подальшого розпізнання медичних зображень захворювань шкіри за допомогою ЗНМ на основі ГН. Це відкриє можливість отримати найточніші результати щодо класифікації медичних зображень захворювань шкіри.

Підсумовуючи виконаний аналіз, можна на його основі запропонувати технічне рішення щодо побудови ЗНМ для класифікації захворювань шкіри для подальших досліджень.

При розробці ЗНМ для класифікації захворювань шкіри доцільно використовувати потужності хмарних технологій, тобто пропонується ЗНМ розгорнути на хмарному сервері, наприклад, таких як GoogleNet, ResNet, QuocNet, тощо для отримання більш точного результату і можливого загального доступу. Модель глибокого навчання, що реалізована в таких інструментах як Tensorflow, Theano, повинна використовуватися для прогнозування ймовірності захворювань шкіри на стороні використовуваного хмарного сервера. Наприклад, ResNet має три параметричних рівня, а кожен шар має 3HM, пакетну нормалізацію, Maxpool i ReLU, що дозволить досягти високих результатів при класифікації захворювань шкіри в майбутньому.

Висновки та перспективи подальшого дослідження. Виконаний аналіз існуючих наукових публікацій щодо класифікації захворювань шкіри при використанні згорткових нейронних мереж показав, що на сьогодні існує незначна кількість публікацій з використанням глибокого навчання. Разом 3 тим, слід відзначити про високі досягнення таких авторів як Haenssle H.A., Fink C., Schneiderbauer R., Toberer F., Buhl T., Blum A., Kalloo A.A., Hassen A. B. H., Thomas L., Enk A., UhlmaHM L., Наo Chang, Гаврилов Д.А. і інших у даному напрямі досліджень. Проте, жоден з них не досягнув достатнього рівня точності і результативності щодо класифікації захворювань шкіри, що підтверджує необхідність розробки нових ЗНМ і їх подальших досліджень.

Також у роботі запропоновано технічне рішення щодо побудови ЗНМ для класифікації захворювань шкіри. Ймовірний склад шарів ЗНМ буде досліджено у наступних роботах.

\section{Список бібліографічний посилань}

1. Ошивалова О.О. Профілактика раку шкіри. Клиническая онкология, 2 (18), 2015. С. 22-24.

2. Pathan, S., Prabhu, K. G., \& Siddalingaswamy, P. C. (2018). Techniques and algorithms for computer aided diagnosis of pigmented skin lesions - A review. Biomedical Signal Processing and Control, 39, 237-262.

3. Lee, H., \& Chen, Y. P. P. (2015). Image based computer aided diagnosis system for cancer detection. Expert Systems with Applications, 42(12), 5356-5365.

4. Kaur, G., \& Aggarwal, E. N. (2016). Supervised Classification of Dermoscopic Images Using Gaussian Mixture Model and Artificial Neural Network. Imperial Journal of Interdisciplinary Research, 2(8).

5. Yuan, X., Yang, Z., Zouridakis, G., \& Mullani, N. (2006, August). SVM-based texture classification and application to early melanoma detection. In Engineering in Medicine and Biology Society, 2006. EMBS'06. 28th AHMual International Conference of the IEEE (pp. 4775-4778). IEEE.

6. Wahba, M. A., Ashour, A. S., Napoleon, S. A., Elnaby, M. M. A., \& Guo, Y. (2017). Combined empirical mode decomposition and texture features for skin lesion classification using quadratic support vector machine. Health information science and systems, 5(1), 10.

7. Barata, C., Marques, J. S., \& Rozeira, J. (2013, July). Evaluation of color based keypoints and features for the classification of melanomas using the bag-of-features model. In International Symposium on Visual Computing (pp. 40-49). Springer, Berlin, Heidelberg. 
8. Ferris, L. K., Harkes, J. A., Gilbert, B., Winger, D. G., Golubets, K., Akilov, O., \& Satyanarayanan, M. (2015). Computer-aided classification of melanocytic lesions using dermoscopic images. Journal of the American Academy of Dermatology, 73(5), 769-776.

9. Xie, F., Fan, H., Li, Y., Jiang, Z., Meng, R., \& Bovik, A. (2017). Melanoma classification on dermoscopy images using a neural network ensemble model. IEEE transactions on medical imaging, 36(3), 849-858.

10. Salah, B., Alshraideh, M., Beidas, R., \& Hayajneh, F. (2011). Skin cancer recognition by using a neuro-fuzzy system. Cancer informatics, 10, CIN-S5950.

11. Burke, H. B. (1994, January). Artificial neural networks for cancer research: outcome prediction. In Seminars in Surgical Oncology (Vol. 10, No. 1, pp. 73-79). New York: John Wiley \& Sons, Inc.

12. Haenssle H.A., Fink C., Schneiderbauer R., Toberer F., Buhl T., Blum A., KallooA A., Hassen A. B. H., Thomas L., Enk A., UhlmaHM L. Man against machine: diagnostic performance of a deep learning convolutional neural network for dermoscopic melanoma recognition in comparison to 58 dermatologists // AHMals of Oncology. 2018. № 8 (29). C. $1836-1842$.

13. Pieter Van Molle, Miguel De Strooper, Tim Verbelen, Bert Vankeirsbilck, Pieter Simoens, and Bart Dhoedt. Visualizing Convolutional Neural Networks to Improve Decision Support for Skin Lesion Classification, arXiv:1809.03851v1 [cs.CV] 11 Sep 2018, pp. 1-8.

14. Hao Chang. Skin cancer reorganization and classification with deep neural network // arxiv.org/ftp/arxiv/papers/1703/1703.00534.pdf

15. Гаврилов Д.А. и др. Автоматизированная диагностика меланомы кожи на основе математической модели искусственной сверточной нейронной сети // Исследования и практика в медицине 2018, т.5, №3, с. 110-116.

16. Гаврилов Д.А. и др. Диагностика меланомы с использованием нейронной сети Inception v3 // Biomedical Image Processing and Analysis GraphiCon 2018. - C. 266-269.

17. Gavrilov D.A., Shchelkunov N.N., Melerzanov A.V. Deep learning based skin lesions diagnosis . The International Archives of the Photogrammetry, Remote Sensing and Spatial Information Sciences, Volume XLII-2/W12, 2019 Int. Worksh. on "Photogrammetric \& Computer Vision Techniques for Video Surveillance, Biometrics and Biomedicine", 13-15 May 2019, Moscow, Russia, 81-85.

18. Esteva, A., Kuprel, B., Novoa, R.A., Ko, J., Swetter, S.M., Blau, H.M., Thrun, S.: Dermatologist-level classification of skin cancer with deep neural networks. Nature 542(7639), 115 (2017), 115-118.

19. Michał Grochowski, Agnieszka Mikołajczyk, Arkadiusz Kwasigroch. Diagnosis of malignant melanoma by neural network ensemble-based system utilising hand-crafted skin lesion features. Metrol. Meas. Syst., Vol. 26 (2019) No. 1, pp. 65-80.

20. Kwasigroch, A., Mikołajczyk, A., Grochowski, M. (2017). Deep neural networks approach to skin lesions classification - A comparative analysis. Methods Models Autom. Robot. MMAR 2017 22nd Int. Conf. On, IEEE, 1069-1074.

21. Kwasigroch, A., Mikołajczyk, A., Grochowski, M. (2017). Deep convolutional neural networks as a decision support tool in medical problems - malignant melanoma case study. Pol. Control Conf., Springer, 848-856.

22. Yu, Z., Jiang, X., Zhou, F., Qin, J., Ni, D., Chen, S., Lei, B., Wang, T. (2018). Melanoma Recognition in Dermoscopy Images via Aggregated Deep Convolutional Features. IEEE Transactions on Biomedical Engineering.

23. Christoph Baur, Salma Farag, Navdar Karabulut, Gurudeep Parala, Abhishek Rana, Shadi Albarqouni, and Nassir Navab. Cascaded DenseNets for Multi-Class Skin Lesion Classification, (2018), 7.

24. Jack Burdick, Florida Atlantic University; Oge Marques, PhD (Presenter); Adrià Romero López; Xavier Giró-i-Nieto; Janet Weinthal. The Impact of Segmentation on the Accuracy and Sensitivity of a Melanoma Classifier Based on Skin Lesion Images // SIIM 2017 Scientific Session Analytics \& Deep Learning Part 3, (2017), 6.

25. Yosinski J, Clune J, Bengio Y, Lipson H: How transferable are features in deep neural networks? Advances in Neural Information Processing Systems, 3320-3328, 2014.

26. Simonyan K, Zisserman A: Very deep convolutional networks for large-scale image recognition. arXiv preprint arXiv:1409.1556, 2014.

27. Russakovsky O, Deng J, Su H, Krause J, Satheesh S, Ma S, Huang Z, Karpathy A, Khosla A, Bernstein M, Berg AC: ImageNet large scale visual recognition challenge. International Journal of Computer Vision 115(3):211-52, 2015. 